\title{
Gene expression profiles of pork samples divergent in intramuscular fat content
}

\author{
O Aslan ${ }^{1,2}$, T Sweeney ${ }^{2}$, A M Mullen ${ }^{1}$, J V O'Doherty ${ }^{2}$, J McBryan $^{1}$, D Morris ${ }^{3}$, R M Hamill ${ }^{1}$ \\ ${ }^{1}$ Teagasc, Ashtown Food Research Centre, Ashtown, Dublin 15, Ireland \\ ${ }^{2}$ UCD, School of Agriculture, Food Science \& Veterinary Medicine, Belfield, Dublin 4, Ireland \\ ${ }^{3}$ Teagasc, Animal Production Research Centre, Mellow Campus, Athenry, Co. Galway, Ireland \\ Email: ozlemasl@gmail.com
}

Introduction Intramuscular fat (IMF) (also referred as marbling) is related to meat eating quality (e.g. flavour, juiciness and tenderness of meat) and IMF levels of pig meat are very important for consumers in relation to healthier options in food choices (Hocquette, et al, 2009; Harper and Pethick, 2004). It has been reported that restriction of lysine in the diet of grower-finisher pigs increases IMF deposition in porcine muscles such as M. semimembranosus (SM) (Zhang et al., 2008). The aim of the present study was to identify the diet-associated gene expression profiles in porcine muscle.

Materials and methods This study involved an experimental diet and a control diet. 11 Duroc origin pigs (female $\mathrm{n}=6$, male $\mathrm{n}=5)$ were placed on the experimental diet which was restricted in lysine $(0.7 \mathrm{~g}$ lysine $/ \mathrm{kg}$ feed $)$ and 11 Duroc origin pigs (female $n=6$, male $n=5$ ) were placed on the control diet which was an isoenergetic but not lysine-restricted diet ( $1.3 \mathrm{~g}$ lysine $/ \mathrm{kg}$ feed). Animals were fed from a mean weight of $46 \mathrm{~kg}$ to slaughter at commercial weight. SM muscle tissues were removed at day 2 post-mortem and IMF \% levels assessed according to the protocol (Bostian, et al, 1985). In parallel, SM tissue was preserved in RNAlater ${ }^{\circledR}$ within 10 minutes of slaughter for microarray analysis. High quality RNA was extracted and hybridised to the Affymetrix GeneChip ${ }^{\circledR}$ porcine array. Rosetta Resolver ${ }^{\circledR}$ was used to estimate fold changes and p-values, and ontologies of differentially expressed genes classified using Panther Protein Classification System (Mi, et al, 2007; Thomas et al, 2003).

Results M. semimembranosus from lysine restricted pigs had significantly higher levels of IMF in comparison to control diet pigs $(3.24 \pm 0.25 \%$ versus $1.73 \pm 0.26 \%$ ) (Table 1$)$ but there was no difference in IMF level between male and femalederived muscle. When analysed separately by gender, IMF levels in SM muscle of Duroc females were significantly affected by restricted diet. Although males on the restricted diet had higher levels of IMF, this was not significant (Table 1). The analysis of the microarray data revealed 477 transcripts were differentially expressed between the restricted diet and the control diet groups. Of the 477 transcripts, 240 and 246 transcripts displayed greater than 1.5-fold increase or decrease in Duroc female and male, respectively at the 0.05 level. 52 differentially expressed genes were identified by using Panther System. Among these 52 genes modulated by diet across genders, several biological processes and molecular functions were significantly over-represented compared to the entire NCBI reference list of human genome $(\mathrm{P}$-value $\leq 0.05)$. These biological processes included amino acid metabolism, signal transduction and lipid, fatty acid and steroid metabolism process whilst over-represented molecular functions included peptide hormone, oxidoreductase, signalling molecule and oxygenase. Gene expression levels and their association with pork quality will be validated using real-time PCR.

Table 1 IMF levels in SM muscle in Duroc population

\begin{tabular}{llll}
\hline \hline & Restricted_diet_(0.7 g lysine $/ \mathrm{kg}$ feed) & Control_diet_(1.3 g lysine $/ \mathrm{kg}$ feed $)$ & $\begin{array}{l}\text { Diet } \\
\text { P-value }\end{array}$ \\
\hline Dean \pm S.E. $(\%)$ & Mean \pm S.E. $(\%)$ & $<0.001$ \\
Duroc (female + male) & $3.24 \pm 0.3$ & $1.73 \pm 0.3$ & 0.02 \\
Duroc male & $3.60 \pm 0.4$ & $1.92 \pm 0.4$ & 0.17 \\
Gender P-value & $2.87 \pm 0.4$ & $1.52 \pm 0.4$ & 0.99 \\
\hline \hline
\end{tabular}

Conclusions These results show that lysine restricted diet resulted in higher levels of IMF content in a commercially important porcine muscle in comparison to control groups. However female derived muscle SM tissue appeared to have greater response to the diet in comparison to male derived muscle in the Duroc breed. Biological processes relevant to fat deposition and amino acid metabolism were significantly over-represented among differentially expressed genes.

Acknowledgements This research was funded by funded by the Irish Department of Agriculture, Fisheries and Food, through the Food Institutional Research Measure.

\section{References}

M. Bostian, Fish, D., Webb, N. and Arey, J. 1985. Journal of the Association of Official Analytical Chemists 68,876

Zhang, J. X. et al., 2008. Asian-Australasian Journal of Animal Sciences 21, 1785

Mi, H. N. Guo, Kejariwal, A. and Thomas, P. 2007. Nucleic Acids Research 35, D247

Thomas, P.D. et al. 2003. Genome Research 13, 2129

Hocquette, J. F., Gondret, F., Baeza, E., Jurie, C. and Pethick, D. W. 2010. Animal 4 (2), 303-319

Harper G.S., Pethick D.W. 2004. Asia Pacific Journal of Clinical Nutrition 2004, 13 